\title{
AVALIAÇÃO DA PRODUÇÃO DE ÁGUA DOS POÇOS TUBULARES UTILIZADOS PARA ABASTECIMENTO PÚBLICO NO MUNICÍPIO DE CARLOS BARBOSA (RS)
}

\author{
Tuane de Oliveira Dutra ${ }^{1}$; Pedro Antonio Roehe Reginato ${ }^{2}$; Marcos Imério Leão ${ }^{2}$; Gustavo Barbosa Athayde ${ }^{2}$; \\ Márcio André Klein ${ }^{3}$; Rosana Alves Paim ${ }^{1}$
}

Resumo - Neste trabalho é apresentada uma avaliação da produção de água dos 15 poços utilizados pela Companhia Riograndense de Saneamento - CORSAN, no munícipio de Carlos Barbosa (RS), que é abastecida exclusivamente por águas subterrâneas, captadas do Sistema Aquífero Serra Geral. No município há 4 reservatórios (R1, R2, R3 e R4), sendo o reservatório R4 abastecido pelo R2, desta forma os poços estudados foram divididos em 3 grupos e a análise foi feita por reservatório. Os dados evidenciaram que a demanda está sendo distribuída de forma desigual nos três grupos de poços. Além disso, o grupo de poços responsável pelo abastecimento do reservatório R1, demostrou que atualmente possui dificuldades em atender a demanda existente, operando com valores de volume médios mensais acima do projetado na maioria dos poços desse grupo.

\begin{abstract}
This paper presents an assessment of the water production of 15 wells used by the Sanitation Companhia Riograndense de Saneamento - CORSAN in the municipality of Carlos Barbosa (RS), which is supplied exclusively by groundwater, captured the Serra Geral Aquifer System. In the municipality there are 4 reservoirs (R1, R2, R3 and R4), being the reservoir 4 Fuelled by R2, thereby the studied wells were divided into 3 groups and the analysis was performed by reservoirs. The data showed that demand is being distributed in an unequal manner in the three groups of wells. Furthermore, the group of wells responsible for supplying the R1 reservoir, demonstrated that currently have difficulties in attend the existing demand, operating with monthly average volume values above projected in most wells of the group.
\end{abstract}

Palavras-Chave - Sistema Aquífero Serra Geral, Aquífero Fraturado, Monitoramento Quantitativo.

\footnotetext{
${ }^{1}$ Programa de Pós Graduação em Recursos Hídricos e Saneamento Ambiental (IPH - UFRGS). Av. Bento Gonçalves, 9500, CEP 91501-970. Porto Alegre, RS. Fone: (51) 33086416. e-mail: tuanehidrica@gmail.com; rosana.a.paim@gmail.com;

${ }^{2}$ Universidade Federal do Rio Grande do Sul (UFRGS), Instituto de Pesquisas Hidráulicas (IPH), Departamento de Hidromecânica e Hidrologia (DHH)

Av. Bento Gonçalves, 9500, CEP 91501-970. Porto Alegre, RS. Fone: (51) 33086416. e-mail: pedro.reginato@ufrgs.br; imerio@iph.ufrgs.br; gustavo.athayde@ufrgs.br;

${ }^{3}$ Companhia Riograndense de Saneamento (CORSAN). Departamento de Pesquisa e Desenvolvimento. Rua Caldas Junior, 120 - 18 andar. Fone: 51 32155634. e-mail: marcio.klein@corsan.com.br
} 


\section{INTRODUÇÃ̃}

Em algumas regiões do país ás águas subterrâneas resultam na única fonte de recurso hídrico disponível. Segundo Leal (1999), o estado do Rio Grande do Sul é um dos estados com maior número de poços juntamente com São Paulo, Bahia, Ceará e Piauí.

Conforme dados do IBGE (2010), no estado do Rio Grande do Sul as águas subterrâneas são a única fonte de abastecimento de 59\% dos municípios. Esse é o caso do Munícipio de Carlos Barbosa, a área de estudo deste trabalho, que está localizado no nordeste do estado e tem como única fonte de abastecimento os poços tubulares, os quais captam água do SASG. Neste município a Companhia Riograndense de Saneamento - CORSAN possui a concessão do abastecimento de água na área urbana.

O SASG abrange cerca de 50\% do estado do Rio Grande do Sul. O SASG está associado a rochas vulcânicas básicas, intermediárias e ácidas, sendo que as duas primeiras atingem juntas mais da metade da área do estado (ROISEMBERG, et al., 2002). Conforme Reginato et. al (2006), a Formação Serra Geral no estado do Rio Grande do Sul, é caracterizada pela presença de aquíferos granulares e fraturados.

Conforme Mourão (2009), a intensidade de aproveitamento dos aquíferos aliadas a falta de informação resulta em severas perdas e impactos como, por exemplo: rebaixamento significativo dos níveis d'água, supressão ou redução de vazões de nascentes, diminuição das vazões de poços tubulares, avanço de cunhas salinas e abatimentos de terrenos. Logo, saber a produção de água dos poços utilizados para o abastecimento no município de Carlos Barbosa é importante para saber se a operação dos mesmos está de acordo com os valores de volume definidos em projeto, prevenindo e reduzindo ao máximo a ocorrência dos impactos citados anteriormente, que teriam efeitos extremamente danosos nesta região abastecida exclusivamente por recursos hídricos subterrâneos.

Desta forma, este trabalho tem como objetivo avaliar a produção dos 15 poços tubulares, utilizados pela CORSAN para abastecer os 4 reservatórios de água existentes no município de Carlos Barbosa. Esta análise foi realizada comparando os dados de produção dos poços fornecidos pela CORSAN com os valores de volume definidos no projeto dos poços, também fornecidos pela companhia.

\section{LOCALIZAÇÃO DA ÁREA DE ESTUDO}

A área de estudo está localizada no município de Carlos Barbosa (Figura 1), na região nordeste do estado do Rio Grande do Sul. Carlos Barbosa está situada a 676 metros acima do nível do mar, entre as coordenadas geográficas $29^{\circ} 18^{\prime}$ de Latitude Sul e $51^{\circ} 30^{\prime}$ de Longitude Oeste e está inserida na região do Planalto dos Campos Gerais. 


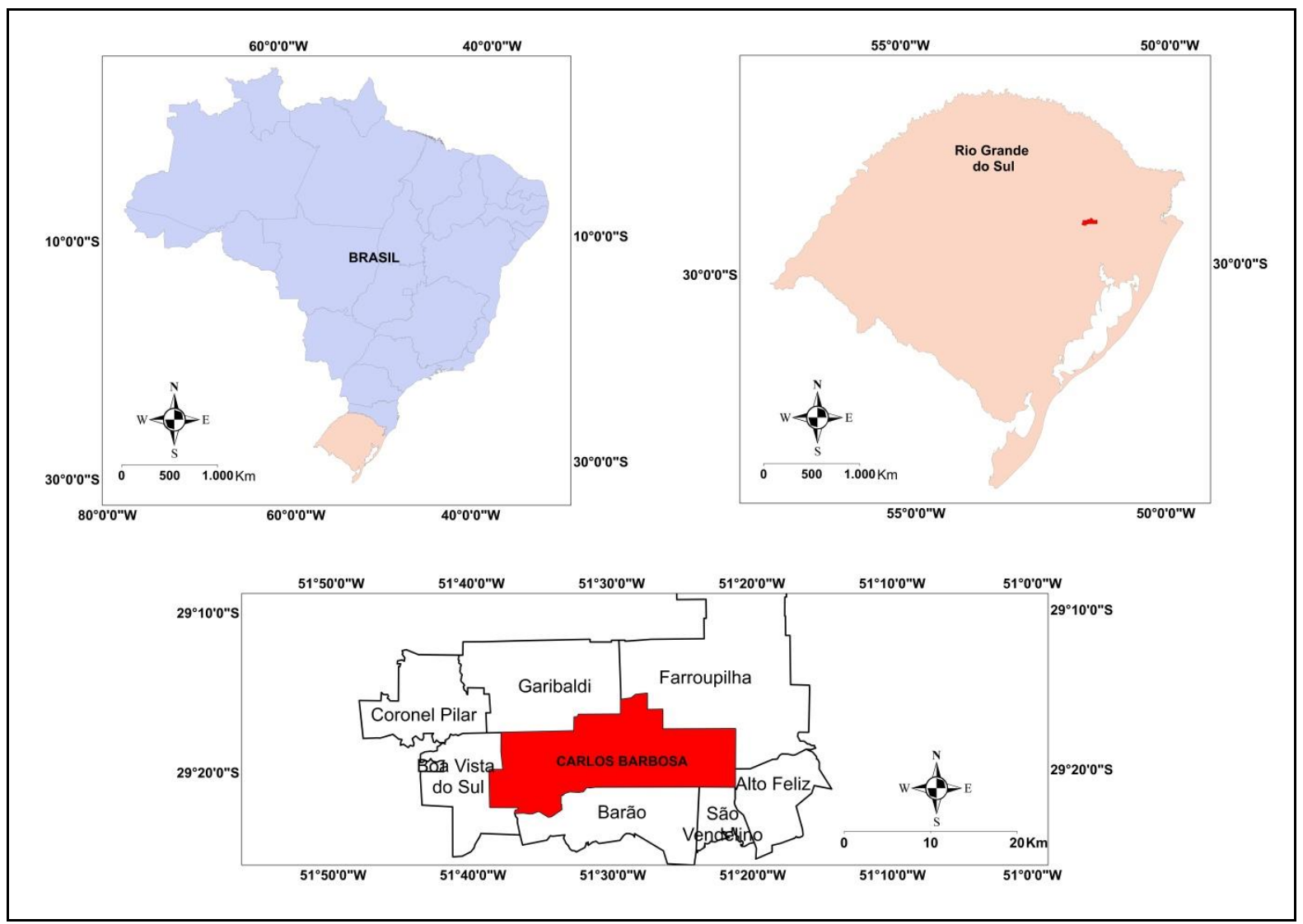

Figura 1. Localização da área de estudo.

O município de Carlos Barbosa esta localizado no divisor de duas bacias hidrográficas, Taquari-Antas e Cai, possuindo $56 \%$ de sua área na primeira bacia e o restante deste percentual na segunda bacia. A cidade possui apenas pequenos arroios que desaguam nestas duas bacias (TaquariAntas e Cai) as quais desaguam na grande bacia do rio Jacuí (PJS GEOLOGIA LTDA, 2013).

\section{METODOLOGIA}

\subsection{Seleção do local de estudo e dos poços tubulares analisados}

O município de Carlos Barbosa foi selecionado, porque neste local o abastecimento de água é realizado exclusivamente por poços tubulares, pertencentes a uma companhia de abastecimento, neste caso a CORSAN, que capta água do Sistema Aquífero Serra Geral. Os 15 poços tubulares analisados neste estudo foram selecionados por serem os utilizados pela CORSAN para o abastecimento do perímetro urbano no município.

\subsection{Levantamento de dados dos poços tubulares e reservatórios analisados}

Os dados dos poços analisados neste trabalho foram disponibilizados pela CORSAN, sendo as informações fornecidas citadas a seguir: coordenadas (geográficas e UTM), teste de bombeamento, 
dados operacionais de projeto, dados mensais de produção. O intervalo de tempo de dados mensais de produção, disponibilizado pela CORSAN, é apresentado da tabela 1 abaixo.

Tabela 1. Período de tempo analisado de dados de volume médio mensal explotado para cada poço

\begin{tabular}{|c|c|c|}
\hline Poços & Intervalo de tempo de monitoramento disponibilizado & $\begin{array}{c}\text { Total de } \\
\text { meses } \\
\text { analisados }\end{array}$ \\
\hline $\begin{array}{l}\text { CBA 3A } \\
\text { CBA 5A }\end{array}$ & Julho de 2009 a dezembro de 2013/ outubro de 2014 a maio de 2016 & 74 \\
\hline $\begin{array}{c}\text { CBA } 6 \\
\text { CBA } 9 \\
\text { CBA } 11 \\
\text { CBA } 12 \\
\text { CBA } 17 \\
\text { CBA } 19 \\
\text { CBA } 18 \\
\end{array}$ & Julho de 2006 a dezembro de 2013/ outubro de 2014 a maio de 2016 & 116 \\
\hline CBA 2 & $\begin{array}{c}\text { Janeiro de } 2010 \text { a setembro de } 2013 \text { / outubro de } 2014 \text { a novembro de } \\
\text { 2015/ Janeiro de } 2016 \text { a maio de } 2016\end{array}$ & 64 \\
\hline CBA 10 & $\begin{array}{l}\text { Janeiro de } 2006 \text { a dezembro de } 2013 \text { / outubro de } 2014 \text { a outubro de } \\
\text { 2015/ Janeiro de } 2016 \text { a maio de } 2016\end{array}$ & 114 \\
\hline CBA 16 & $\begin{array}{c}\text { Janeiro de } 2006 \text { a abril de } 2012 / \text { julho de } 2012 \text { a dezembro de 2013/ } \\
\text { outubro de } 2014 \text { a maio de } 2016\end{array}$ & 114 \\
\hline CBA 20 & $\begin{array}{c}\text { Janeiro de } 2006 \text { a setembro de 2012/ novembro de } 2012 \text { a dezembro } \\
\text { de } 2013 \text { / outubro de } 2014 \text { a maio de } 2016\end{array}$ & 115 \\
\hline CBA 26 & $\begin{array}{l}\text { Março de } 2013 \text { a dezembro de } 2013 / \text { fevereiro de } 2014 \text { a maio de } \\
2016\end{array}$ & 38 \\
\hline CBA 34 & $\begin{array}{c}\text { Janeiro de } 2010 \text { a setembro de 2013/ outubro de } 2014 \text { a novembro de } \\
\text { 2015/ Janeiro de } 2016 \text { a maio de } 2016\end{array}$ & 65 \\
\hline
\end{tabular}

Em relação aos quatro reservatórios de água utilizados para abastecimento do município a CORSAN forneceu os seguintes dados: localização, capacidade em $\mathrm{m}^{3}$ e relação de poços utilizados em cada reservatório.

\subsection{Avaliação do monitoramento executado pela CORSAN}

Essa avaliação foi realizada, inicialmente, através da obtenção de informações sobre o sistema de monitoramento operado pela CORSAN, que foram obtidas junto a Superintendência de Hidrogeologia da CORSAN e a Unidade da CORSAN localizada no município de Carlos Barbosa (escritório local). 
Posteriormente foi realizada uma atividade de campo onde foi feito o acompanhamento da atividade de monitoramento realizada pelo técnico da CORSAN, para avaliar o processo, a forma e os dados que eram obtidos com esse monitoramento.

Essa etapa foi importante para saber a forma de coleta dos dados que foram trabalhados neste estudo e poder melhor interpretar os comportamentos dos mesmos.

\subsection{Análise da produção dos poços responsáveis pelo abastecimento}

Esta etapa do trabalho foi realizada através da comparação gráfica entre os dados de produção de água dos poços (volume médio mensal $\mathrm{em}^{3}$ ), fornecidos pela CORSAN, com os dados de projetos elaborados para os poços. Está análise foi feita para um intervalo mensal de tempo, o qual foi descrito anteriormente na tabela 1.

Para melhor entender a variação da produção dos poços foi aplicada algumas análises estatísticas que envolveram:

- Medidas de tendência central: mediana (devido a grande variação dos dados);

- Medida de dispersão: desvio padrão.

Também foi verificado a porcentagem de tempo monitorado em que o volume médio de água extraído ficou acima do projetado, quando isso ocorreu, sendo calculado também a mediana dos valores ultrapassados.

No município existem 4 reservatórios (R1, R2, R3 e R4), sendo que o reservatório R2 abasteci o reservatório R4. Como cada um desses reservatório é atendido por um grupo de poços específico, a análise da produção de água para abastecimento publico no município foi feita por reservatório. Desta forma, é possível analisar o atendimento as demandas existentes em cada reservatório e a distribuição da mesma entre os poços de cada grupo.

Os poços da CORSAN CBA 4A e CBA 10, tiveram seu funcionamento interrompido, o primeiro em setembro de 2014 e o segundo nos meses de novembro e dezembro de 2015, o primeiro é um dos poços responsáveis pelo abastecimento do reservatório R1 e o segundo pelo reservatório R2. No caso do poço CBA 10 o mesmo retornou a funcionar em janeiro de 2016, já o poço CBA 4A por ter apresentado problemas estruturais foi desativado, tendo sido perfurado um novo poço ao lado deste, o qual ainda não entrou em funcionamento. Levando em consideração a boa capacidade de produção de ambos os poços, foi analisada a influência da ausência dos mesmos nas operações dos poços. 


\section{RESULTADOS}

\subsection{Monitoramento quantitativo realizado pela CORSAN}

Atualmente a CORSAN possui 15 poços para atender o município de Carlos Barbosa, os quais serão analisados neste trabalho. Os parâmetros monitorados pela companhia são: volume explotado, tempo de bombeamento e níveis de água. Essas informações são coletadas manualmente por um técnico da CORSAN, por meio de visitas aos poços.

O volume explotado é medido por meio de hidrômetro, (Figura 2.A). Na ausência do hidrômetro o volume é calculado através da vazão, a qual é estimada pelo método volumétrico (utilizando tonel). A definição do tempo de operação da bomba é realizada por dois sistemas: Timer (Figura 2.B) e a Rádio, já o Horimetro é utilizado para registrar o tempo total de funcionamento da bomba.
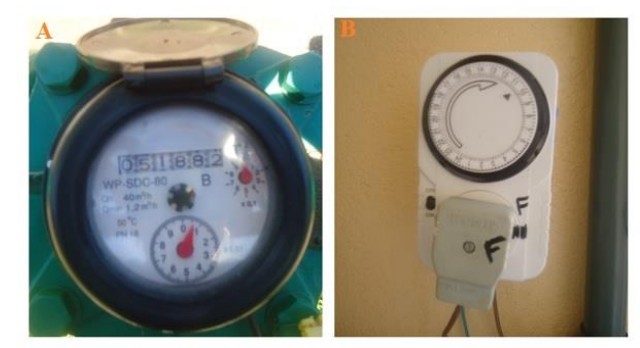

Figura 2. (A) Hidrômetro (B) Timer.

Os poços que possuem Timer trabalham apenas dentro do tempo de bombeamento projetado, logo quando esse tempo é atingido o Timer encerra o bombeamento do poço e inicia novamente após o tempo de descanso previsto. Porém com o aumento da demanda o Timer é desligado para o poço voltar a bombear, conforme informações fornecidas pelo técnico da CORSAN responsável pelo monitoramento. Os poços que possuem somente o sistema a rádio trabalham em função dos reservatórios, os quais eles abastecem.

A produção e o tempo de bombeamento mensal são calculados de duas formas:

- Primeira: diferença das leituras feitas no primeiro e no último dia de cada mês

- Segunda: somatório das leituras diárias

Há diferença entre os valores registrados, pois os cálculos que adotam o primeiro e ultimo valor observado no mês, consideram apenas o valor da amplitude do volume e do tempo de bombeamento, no entanto, essas diferenças são pequenas.

O método volumétrico descrito anteriormente é seguidamente aplicado para o calculo da vazão e volume de água bombeado, sendo que o mesmo sempre registra valores médios de volume 
significativamente inferiores aos comumente monitorados pelos hidrômetros, quando estes estão em funcionamento.

O fato de o monitoramento ser realizado de forma manual e ter poucos funcionários para a realização do mesmo, inviabiliza que a coleta dos dados ocorra sempre no mesmo horário, podendo ser registrados valores de volume de água superiores e/ou inferiores aos realmente extraídos dos aquíferos.

Além disso, os níveis de água são medidos pela CORSAN nos poços de forma aleatória, sem frequência ou periodicidade definida, por meio da utilização de medidores de nível de água manuais. Essas leituras não são realizadas necessariamente no final do período de maior tempo de bombeamento e sem bombeamento, as quais representariam possivelmente os níveis mínimos e máximos atingidos no poço. Logo, os dados coletados pela CORSAN de níveis de água não auxiliam, de forma efetiva, na análise dos reflexos da explotação contínua dos poços sobre o aquífero.

Em 2014 iniciou-se a implantação de um sistema de monitoramento quantitativo totalmente automatizado em Carlos Barbosa, denominado de SIGAS. Este sistema monitora o nível de água de 1 em 1 minuto e os parâmetros de vazão e volume de 15 em 15 minutos. O SIGAS foi instalado em 12, dos 15 poços analisados neste trabalho, ficando de fora apenas os poços CBA 2, 6 e 20. Conforme Dutra et. al (2016), em análise em dois poços que possuem o SIGAS instalado, este sistema se demostrou eficiente e proporcionou uma descrição mais detalhada da produção dos poços e dos reflexos da operação dos mesmos no nível da água no poço. Atualmente os dois sistemas (SIGAS e CORSAN) estão em funcionamento no município, sendo que em alguns poços o SIGAS ainda necessita de alguns ajustes. Contudo, em pleno funcionamento, irá favorecer de forma impar, o gerenciamento dos recursos hídricos subterrâneos no munícipio de Carlos Barbosa.

\subsection{Caracterização dos poços tubulares responsáveis pelo abastecimento}

Os quinze poços analisados possuem características hidrodinâmicas relativamente variadas. Na tabela 2, são apresentados alguns dados hidrodinâmicos desde grupo de poços analisados, proporcionando uma noção das características dos mesmos. Os dados do poço CBA 4A foram apresentados ao final da tabela 2, para demostrar a grande importância que o mesmo tinha para o abastecimento do reservatório R1. Este poço possuía o segundo maior valor de vazão e terceiro maior valor de capacidade especifica do grupo de poços responsável pelo abastecimento do reservatório $\mathrm{R} 1$. 
Tabela 2. Dados hidrodinâmicos dos poços analisados

\begin{tabular}{|c|c|c|c|c|c|c|c|c|}
\hline POÇOS & $\begin{array}{c}\text { PROF. } \\
(\mathbf{m})\end{array}$ & $\begin{array}{c}\text { PROF. EA } \\
\quad(\mathrm{m})\end{array}$ & $\begin{array}{c}\text { PROF. } \\
\text { REV } \\
(\mathrm{m})\end{array}$ & ND (m) & NE (m) & $\begin{array}{c}\mathbf{Q} \\
\left(\mathbf{m}^{\mathbf{3}} / \mathbf{h}\right)\end{array}$ & $\begin{array}{c}\mathbf{q} / \mathbf{s} \\
\left(\mathbf{m}^{3} / \mathbf{h} . \mathbf{m}\right)\end{array}$ & TB (h) \\
\hline CBA 2 & 74,8 & 15,5 e 52,7 & 6,3 & 38,4 & 30,3 & 13,655 & 1,686 & 12 \\
\hline CBA 3A & 163,65 & $21 ; 26$ e 159 & 32 & 110 & 22,2 & 45 & 0,513 & 16 \\
\hline CBA 5A & 216 & 40 & 26,3 & 40 & 6,25 & 12 & 0,356 & 16 \\
\hline CBA 6 & 40 & 37 & 10,5 & 25,48 & 3,54 & 16 & 0,729 & 12 \\
\hline CBA 9 & 71,5 & $19 ; 23,5$ e 53,5 & 15,3 & 35 & 15,2 & 30 & 1,515 & 18 \\
\hline CBA 10 & 90 & 8,5 e 14,3 & 10 & 20 & 7,1 & 25 & 1,938 & 16 \\
\hline CBA 11 & 98 & 14 e 22 & 12,5 & 35 & 5,38 & 30 & 1,013 & 16 \\
\hline CBA 12 & 86 & $5 ; 21$ e 61 & 13 & 24 & 10,3 & 20 & 1,460 & 12 \\
\hline CBA 16 & 114 & 56,3 & 53,35 & 45,96 & 1,36 & 25,352 & 0,568 & 14 \\
\hline CBA 17 & 141,5 & 3 e 101 & 10 & 36 & 0,15 & 24 & 0,669 & 10 \\
\hline CBA 18 & 150 & 56 e 80 & 1,69 & 87,85 & 2,54 & 13,31 & 0,156 & 12 \\
\hline CBA 19 & 122 & $34 ; 38$ e 112 & 2,44 & 26 & 2,44 & 50 & 2,122 & 14 \\
\hline CBA 20 & 140 & 74 & 4,8 & 33,97 & 11,55 & 24,94 & 1,112 & 12 \\
\hline CBA 26 & 150 & 34 e 70 & 36,5 & 70 & 5,78 & 10 & 0,156 & 10 \\
\hline CBA 34 & 180 & $48 ; 60$ e 71 & 30 & 70,12 & 16,2 & 15,99 & 0,297 & 14 \\
\hline CBA 4A & 162 & 158 & 14 & 85 & 44,84 & 35 & 0,872 & 16 \\
\hline
\end{tabular}

PROF: Profundidade/ EA: Entrada de água/ REV: Revestimento/ ND: Nível dinâmico/ NE: Nível estático/ Q: Vazão/ q/s: Capacidade específica/ TB: Tempo de bombeamento.

A profundidade dos poços analisados varia de 40 a $216 \mathrm{~m}$, sendo que na maioria dos poços a mesma se encontra abaixo dos 100 m, com exceção somente dos poços CBA 2, 6, 9, 10, 11 e 12.

As entradas de água possuem significativa variação de profundidade, sendo a mais superficial registrada no poço CBA 17 aos $3 \mathrm{~m}$ e a mais profunda no poço CBA 3A aos $159 \mathrm{~m}$. Os poços possuem de 1 a 3 entradas de águas, conforme descrito a seguir:

- Uma entrada de água: poços CBA 5A, 6, 20 e 16;

- Duas entradas de água: poços CBA 2, 10, 11, 17, 18 e 26;

- Três entradas de água: poços CBA 3A, 9, 12, 19 e 34.

No entanto, devido à profundidade do revestimento, as entradas de água mais superficiais nos poços CBA 3A, 10, 12, 17 e 26 foram seladas.

O nível dinâmico (ND), na maioria dos poços, está situado acima dos $50 \mathrm{~m}$ de profundidade, sendo que o ND mais superficial está situada no poço CBA 10 aos $20 \mathrm{~m}$ e o mais profundo no poço CBA $3 \mathrm{~A}$ aos $110 \mathrm{~m}$.

O nível estático (NE), em grande parte dos poços é superficial, situado acima dos $10 \mathrm{~m} \mathrm{de}$ profundidade, sendo que o NE mais próximo a superfície, se encontra a apenas $0,15 \mathrm{~m}$ da mesma, no poço CBA 17 e o mais profundo no poço CBA 2 aos $30,3 \mathrm{~m}$. 
As vazões de projeto variam de 10 a $50 \mathrm{~m} 3 / \mathrm{h}$, sendo a ultima vazão citada a maior registrada no munícipio de Carlos Barbosa. As vazões de projeto são coerentes com as que ocorrem no sistema aquífero fraturado, que em geral são baixas. No entanto, os poços analisados podem ser divididos em 3 grupos em relação a vazão. O primeiro grupo é constituído pelos poços CBA 2, 5A, 6, 18, 26 e 34, que possuem vazões baixas, inferiores a $20 \mathrm{~m}^{3} / \mathrm{h}$. O segundo grupo é constituído dos poços CBA 10, 12, 16, 17 e 20, que possuem vazões intermediárias, as quais são igual a $20 \mathrm{~m}^{3} / \mathrm{h} \mathrm{e}$ interiores a $30 \mathrm{~m} 3 / \mathrm{h}$. O terceiro grupo é referente aos poços CBA 3A, 9, 11 e 19, que possuem as vazões mais elevadas, as quais são iguais e/ou superiores a $30 \mathrm{~m} / \mathrm{h}$. A capacidade específica em todos os poços é baixa, sendo que na maioria deles é inferior a $1 \mathrm{~m} / \mathrm{h} / \mathrm{m}$.

Em relação ao tempo de bombeamento projetado, este varia de 10 a 18 horas, sendo na maioria dos poços de 12 e 16 horas.

\subsection{Reservatórios responsáveis pelo abastecimento em Carlos Barbosa}

Os poços caracterizados no item anterior abastecem os quatro reservatórios existentes no município, conforme apresentado na tabela 3.

Tabela 3. Relação dos reservatórios e os poços que o abastecem.

\begin{tabular}{ccc}
\hline Reservatórios & Volume $\left(\mathbf{m}^{\mathbf{3}}\right)$ & Poços \\
\hline R1 & 500 & $2,3,5,6,18,20,26$ e 34 \\
R2 & 200 & $9,10,11$, e 12 \\
R3 & 200 & 16,17 e 19 \\
R4 & 30 & Abastecido pelo R2 \\
\hline
\end{tabular}

No reservatório 4 o nível é controlado através de uma boia e nos demais reservatórios através de sensores de nível. Os controladores de níveis mencionados emitem um sinal via rádio para o poço, sendo que o mesmo possui em seu quadro de comando cinco níveis de água 1, 2, 3, 4 e 5 (sendo 1 o nível mais baixo e o cinco quando o reservatório está cheio) logo o poço é sempre acionado quando o reservatório chega ao nível 3 e desligado quando mesmo se encontra no nível 5. Sendo assim, os poços que só possuem o sistema a rádio para controlar o tempo de bombeamento do poço, tem seu tempo de bombeamento regulado pela demanda do reservatório, que é o caso dos poços CBA 3A, 17 e 19.

Na figura 3 é apresentado os reservatórios e os poços responsáveis pelo bombeamento dos mesmos. Como é possível observar, há outros poços situados no perímetro urbano de Carlos Barbosa. Sendo que, nas proximidades dos poços analisados predominam poços em operação, os quais em sua maioria são utilizados para manutenção de atividades econômicas. Logo, a análise da 
produção dos poços utilizados pela CORSAN é importante, para saber se está sendo extraído do aquífero o volume determinado em projeto. Se o volume de água explotado for superior ao projetado, pode comprometer o atendimento aos outros tipos de demandas existentes no munícipio.

O poço CBA 4A também foi identificado no mapa, porque o mesmo era utilizado para o abastecimento do reservatório R1. No entanto, o mesmo foi desativado, sendo analisado no próximo item o reflexo desta ausência na produção dos demais poços responsáveis pelo abastecimento deste reservatório.

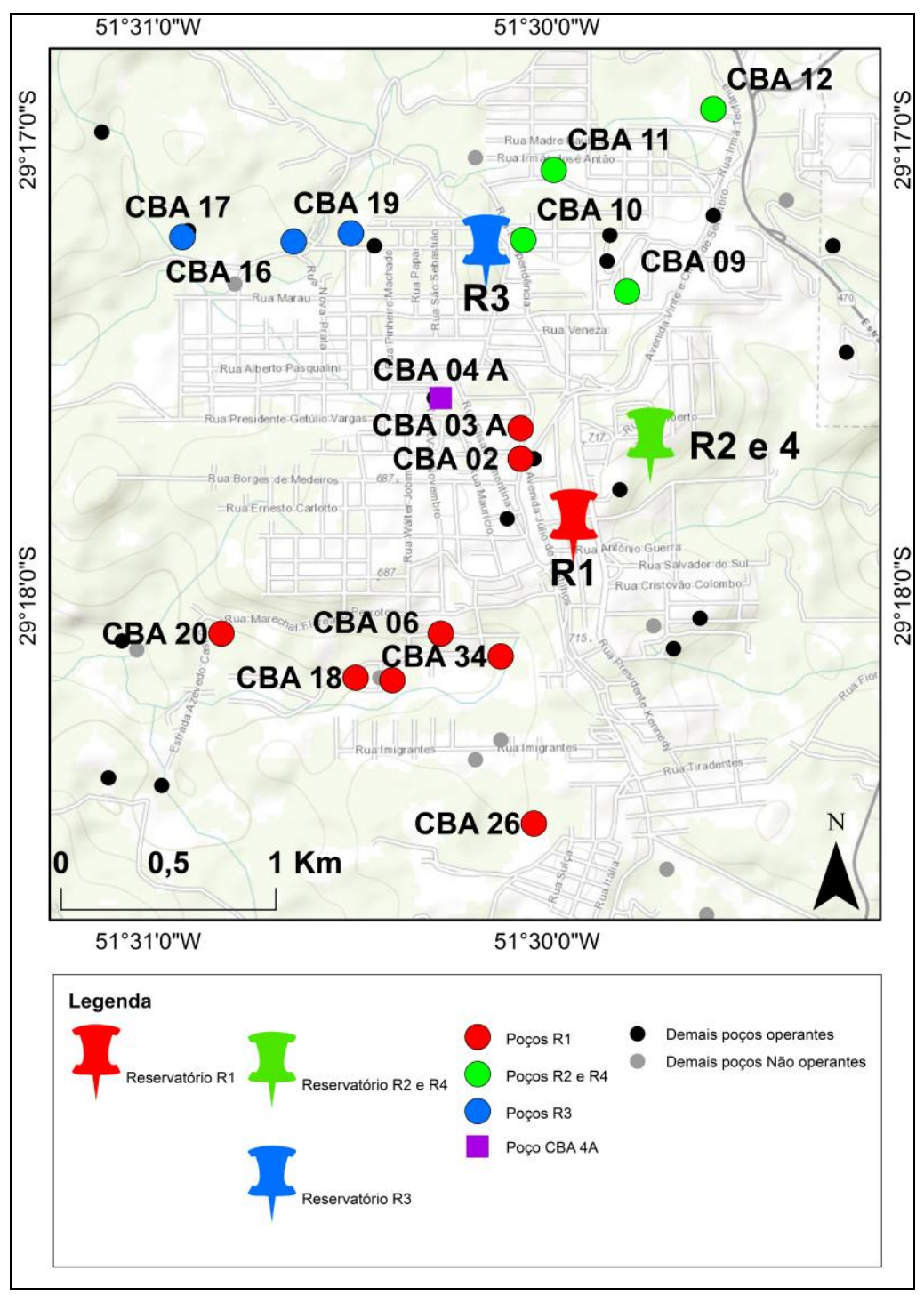

Figura 3. Localização dos reservatórios e poços analisados

\subsection{Produção dos poços responsáveis pelo abastecimento do reservatório R1}

Este reservatório atualmente conta com 8 poços para o seu abastecimento, sendo o principal reservatório do município, possuindo cerca de 54\% da capacidade de armazenamento do mesmo. 
Todos os poços desse grupo, em algum momento, explotaram volumes de água superiores ao projetado, sendo que a mediana dos valores ultrapassados de volume nesses grupos de poços é relativamente baixa, não ultrapassando os $35 \mathrm{~m}^{3}$ (Tabela 4).

Nos poços CBA 3A e 5A a mediana dos valores médios mensais de volume explotado estão abaixo do projetado, sendo a porcentagem do período monitorado, em que o volume projetado foi ultrapassado, inferior a 5\% (Tabela 4). Nos poços CBA 2 e 6 a mediana dos valores médios mensais de volume explotado também ficaram abaixo do projetado, no entanto, a porcentagem do período monitorado em que o volume projetado foi ultrapassado foi mais significativa, em relação aos poços anteriores, de 43,75 e 19,13\% respectivamente. Nos poços CBA 18, 20, 26 e 34, ocorreu o oposto do que foi observado nos quatro poços anteriores, a mediana dos valores médios mensais de volume explotado nesses poços foi superior ao projetado, sendo que nesses quatro poços , a porcentagem do período monitorado em que o volume projetado foi ultrapassado foi superior a 50\%. Os poços CBA 20 e 34 tiveram um novo teste de bombeamento, no primeiro poço foi no final de 2014 e no segundo poço foi no início de 2015, alterando os seus dados de projeto e consequentemente o volume projetado. Os valores apresentados na tabela 4 , desses dois poços, são referentes ao primeiro teste de bombeamento, sendo que os valores correspondentes aos novos testes de bombeamento só entraram em vigor no final da série de dados monitorados.

Tabela 4. Dados de produção do grupo de poços responsável pelo abastecimento do reservatório $\mathrm{R} 1$.

\begin{tabular}{|c|c|c|c|c|c|}
\hline Poços & $\begin{array}{c}\text { Volume } \\
\text { projetado } \\
\left(\mathbf{m}^{3}\right)\end{array}$ & $\begin{array}{c}\text { Mediana do } \\
\text { vol. explotado } \\
\left(\mathbf{m}^{3}\right)\end{array}$ & $\begin{array}{l}\text { Desvio padrão } \\
\text { do vol. } \\
\text { explotado }\left(\mathbf{m}^{3}\right)\end{array}$ & $\begin{array}{c}\text { \% do tempo } \\
\text { monitorado que o } \\
\text { Vol. foi ultrapassado } \\
\text { (h) }\end{array}$ & $\begin{array}{c}\text { Mediana do } \\
\text { valor de vol. } \\
\text { Ultrapassado } \\
\left(\mathbf{m}^{3}\right)\end{array}$ \\
\hline CBA 2 & 163,86 & 159,11 & 27,65 & 43,75 & 11,54 \\
\hline CBA $3 \mathrm{~A}$ & 720 & 305,96 & 176,90 & 1,35 & 15,93 \\
\hline CBA $5 A$ & 192 & 126,96 & 37,00 & 4,05 & 7,14 \\
\hline CBA 6 & 192 & 144,06 & 41,38 & 19,13 & 14,49 \\
\hline CBA 18 & 159,72 & 161,23 & 40,41 & 53,45 & 17,79 \\
\hline CBA 20 & $240^{*}$ & 243,56 & 31,03 & 58,26 & 15,20 \\
\hline CBA 26 & 100 & 132,28 & 17,44 & 94,74 & 33,13 \\
\hline CBA 34 & $144 * *$ & 174,10 & 39,22 & 76,92 & 30,04 \\
\hline
\end{tabular}

O desvio padrão dos valores médios mensais de volume explotado é variado, conforme apresentado na tabela 4, sendo que no poço CBA 3A este desvio é mais significativo em comparação 
aos demais poços. O comportamento da variação dos valores médios de volumes explotados nos oito poços analisados podem ser visualizados na figura 4.

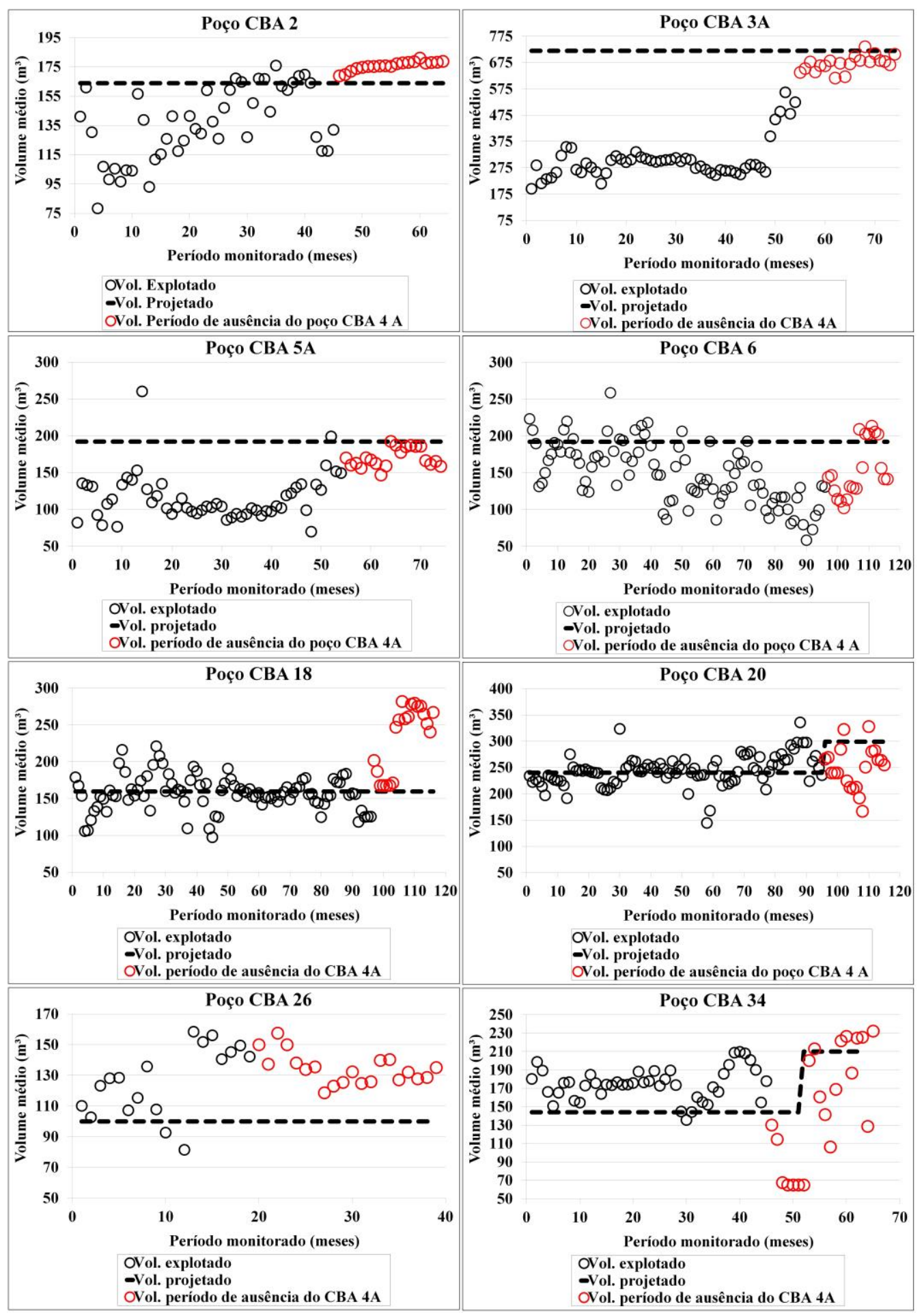

Figura 4.Valores médios mensais de volume de água explotado nos poços utilizados para o abastecimento do reservatório R1.

O poço CBA 4A, também abastecia este reservatório, sendo o segundo mais produtivo, atrás apenas do poço CBA 3A. No entanto, o mesmo foi desativado em setembro de 2014, por causa de 
problemas estruturais. A influência da ausência deste poço na operação dos demais poços do grupo pode ser visualizada através dos círculos vermelhos nos gráficos da figura 4. Logo, é possível notar que com exceção do poço CBA 26, todos os poços apresentaram uma elevação nos valores de volume extraídos, em relação ao período anterior a desativação do poço CBA 4A. Contudo, esta elevação do volume explotado não foi a mesma em todos os poços, sendo mais intensa nos poços CBA 2 e 18 e mais sutil nos poços CBA 6, 20 e 34. Já nos poços CBA 3A e 5A a ausência deste poço somente intensificou uma tendência de aumento que já estava ocorrendo.

Nos últimos anos (final de 2014 até maio de 2016), no reservatório R1, ocorreram duas situações:

- A primeira está relacionada aos poços que estão explotando, habitualmente, valores de volume médio mensal acima do projetado, que é o caso dos poços CBA 2, 6, 18, 26 e 34;

- A segunda está relacionada aos poços que estão com os valores de volume médio mensal muito próximo ao limite do permitido em projeto, ultrapassando o mesmo apenas uma e/ou duas vezes, que é o caso dos poços CBA 3A, 5A e 34.

Logo, os poços que estão extraindo volumes de água acima do projetado não teriam a pressão sobre eles reduzida pelo aumento do volume explotado nos demais poços, sendo que os mesmos já se encontram muito próximo dos limites máximos de produção de água permitida. $\mathrm{O}$ aumento da demanda a ser atendida por esse grupo de poços, em parte ocorreu pela falta do poço CBA 4A. Contudo, este possivelmente não seja o único motivo, a demanda antes da desativação do poço CBA 4 A já estava demostrando sinais de aumento, os quais foram observados nos poços CBA 3A e 5A, com a tendência de elevação dos valores de volume médios mensais explotados. Sendo assim, a produção de água projetada desse grupo de poços existentes para o atendimento da demanda do reservatório R1 já demostra ser insuficiente.

\subsection{Produção dos poços responsáveis pelo abastecimento do reservatório $R 2$ e $\mathbf{R} 4$}

O reservatório R2 possuí cerca de 21,5\% da capacidade de armazenamento do município, sendo responsável também pelo abastecimento do R4 o qual possuí cerca de $3 \%$ da capacidade de armazenamento total de Carlos Barbosa. Logo, o reservatório R2 é o segundo principal reservatório do município, sendo abastecido pelos poços CBA 9, 10, 11, e 12.

Com exceção do poço CBA 11, as medianas dos valores médios mensais de volume explotado foram inferiores ao projetado. No poço CBA 11, valores acima do projetado foram registrados em mais de $50 \%$ do período monitorado, sendo que a mediana do valor ultrapassado foi de $20,37 \mathrm{~m}^{3}$ (Tabela 5). 
Os poços CBA 9, 10 e 11, tiveram um novo teste de bombeamento no final do ano de 2014, alterando os seus dados de projeto e consequentemente o volume projetado. Os valores apresentados na tabela 5, para esses três poços, são referentes ao primeiro teste de bombeamento, sendo que os valores correspondentes aos novos testes de bombeamento só entraram em vigor no final da série de dados monitorados.

Tabela 5. Dados de produção do grupo de poços responsável pelo abastecimento do reservatório $\mathrm{R} 2$ e $\mathrm{R} 4$.

\begin{tabular}{|c|c|c|c|c|c|}
\hline Poços & $\begin{array}{l}\text { Volume } \\
\text { projeta } \\
\text { do }\left(\mathbf{m}^{3}\right)\end{array}$ & $\begin{array}{c}\text { Mediana do } \\
\text { vol. explotado } \\
\qquad\left(\mathbf{m}^{3}\right)\end{array}$ & $\begin{array}{l}\text { Desvio padrão } \\
\text { do vol. } \\
\text { explotado }\left(\mathrm{m}^{3}\right)\end{array}$ & $\begin{array}{c}\% \text { do tempo } \\
\text { monitorado que o } \\
\text { Vol. foi } \\
\text { ultrapassado (h) }\end{array}$ & $\begin{array}{l}\text { Mediana do valor } \\
\text { de vol. } \\
\text { Ultrapassado }\left(\mathrm{m}^{3}\right)\end{array}$ \\
\hline CBA 9 & $264 *$ & 197,48 & 36,64 & $\ldots \ldots .$. & ........ \\
\hline CBA 10 & $400 * *$ & 182,13 & 35,42 & ....... & ........ \\
\hline CBA 11 & $240 * * *$ & 249,96 & 42,71 & 54,31 & 20,37 \\
\hline CBA 12 & 240 & 117,64 & 27,78 & ....... & ........ \\
\hline
\end{tabular}

Neste grupo de poços, apenas no poço CBA 11 foi observado valores médios mensais de volume explotado superior ao projetado (Tabela 5). Contudo, tais registros ocorreram somente antes do novo teste de bombeamento. Após o novo teste no poço CBA 11, foram registrados valores acima do projetado somente no período de ausência do poço CBA 10 (Figura 5). 


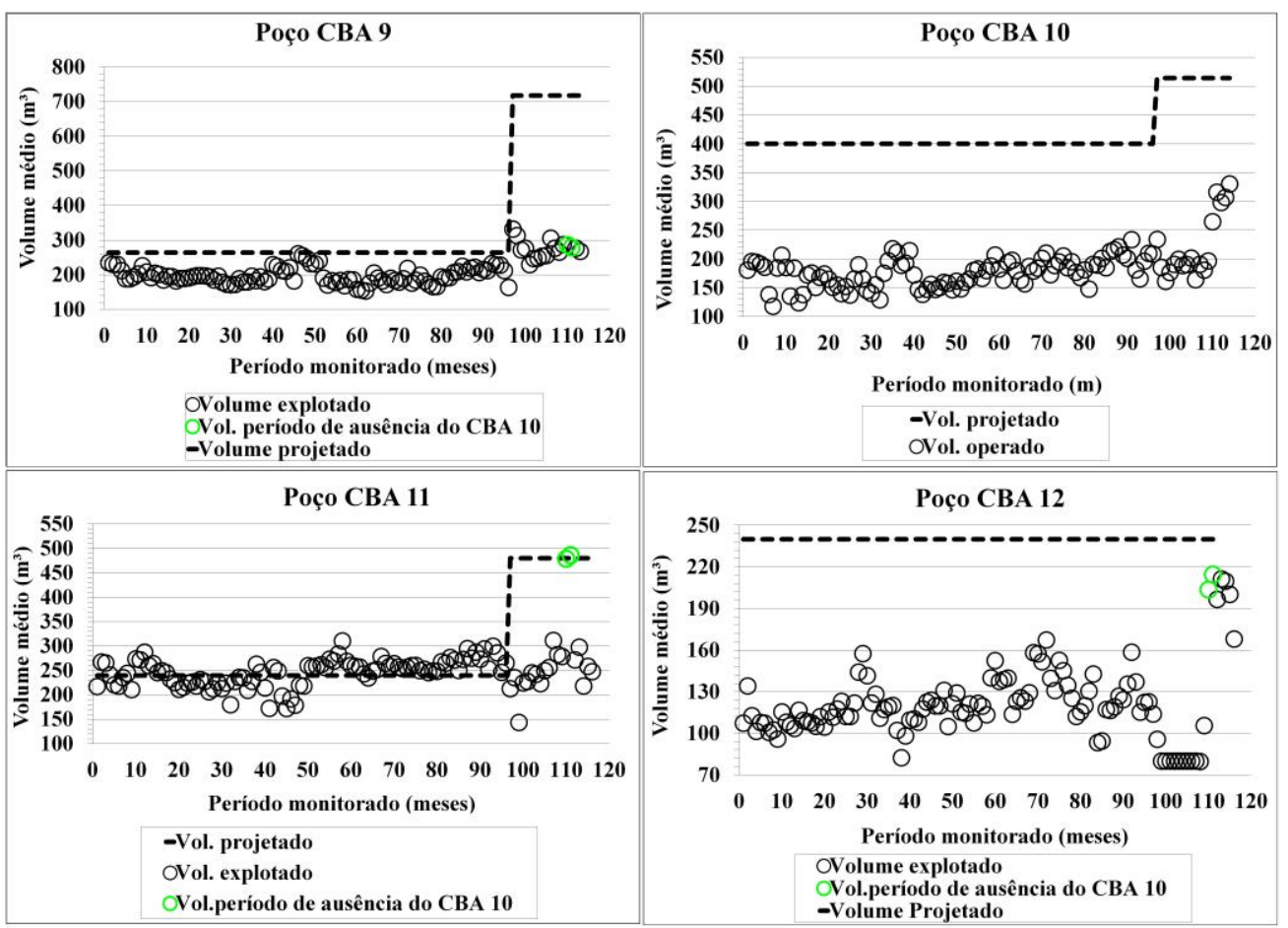

Figura 5. Valores médios mensais de volume de água explotado nos poços utilizados para o abastecimento dos reservatórios R2 e R4.

O poço CBA 10 é um dos poços responsáveis pelo abastecimento no R2, o mesmo ficou desativado nos meses de novembro e dezembro de 2015, retornando em janeiro de 2016. Este poço é o segundo mais produtivo, ficando atrás apenas do poço CBA 9, sendo que a interrupção no seu bombeamento refletiu nos demais poços. Na figura 5, fica claro que a demanda do poço CBA 10 , foi atendida de forma mais intensa pelos poços CBA 11 e 12, os quais demostraram um aumento significante, em relação aos volumes comumente extraídos. No poço CBA 9 a influência da falta do poço CBA 10, foi mais sutil, sendo difícil de ser observada a partir dos dados mensais de volume da CORSAN, levando em consideração também que os valores de volume já estavam apresentando uma tendência de aumento neste período.

Nos últimos anos (final de 2014 até maio de 2016), os valores de volumes médios mensais de água extraídos para o abastecimento público nesse grupo de poços, estão abaixo do valor definido em projeto.

\subsection{Produção dos poços responsáveis pelo abastecimento do reservatório $\mathbf{R 3}$}

Este reservatório possuí $21,5 \%$ da capacidade de armazenamento do município, sendo abastecido pelos poços CBA 16, 17 e 19. Desses poços apenas o poço 16, na totalidade do período monitorado, não ultrapassou o volume projetado. No poço CBA 17, o oposto ocorreu, ou seja, em quase que na totalidade do período monitorado os valores de mediana dos volumes médios mensais 
explotados foram superiores ao projetado, sendo que no poço CBA 19 o mesmo comportamento foi observado, só que em cerca de $13 \%$ do tempo, conforme tabela 6 . A mediana dos valores de volume ultrapassado foi elevada no poço CBA 17, quase $100 \mathrm{~m}^{3}$. Logo, somente neste poço o valor de mediana dos volumes médios mensais foi superior ao projetado. Já no poço CBA 19 o valor de mediana do volume ultrapassado foi baixo, de 23,68 $\mathrm{m}^{3}$.

Tabela 6. Dados de produção do grupo de poços responsável pelo abastecimento do reservatório $\mathrm{R} 3$.

\begin{tabular}{cccccc}
\hline Poços & $\begin{array}{c}\text { Volume } \\
\text { projetado } \\
\left(\mathbf{m}^{\mathbf{3}}\right)\end{array}$ & $\begin{array}{c}\text { Mediana do } \\
\text { vol. explotado } \\
\left(\mathbf{m}^{\mathbf{3}}\right)\end{array}$ & $\begin{array}{c}\text { Desvio padrão } \\
\text { do vol. } \\
\text { explotado }\left(\mathbf{m}^{\mathbf{3}}\right)\end{array}$ & $\begin{array}{c}\text { \% do tempo } \\
\text { monitorado que o } \\
\text { Vol. foi } \\
\text { ultrapassado }(\mathbf{h})\end{array}$ & $\begin{array}{c}\text { Mediana do valor } \\
\text { Ultrapassado }\left(\mathbf{m}^{\mathbf{3}}\right)\end{array}$ \\
\hline CBA 16 & 350 & 135,85 & 43,24 & $\ldots \ldots$. & $\ldots \ldots$. \\
CBA 17 & 240 & 335,17 & 57,26 & 94,83 & 99,26 \\
CBA 19 & 700 & 636,83 & 80,07 & 13,79 & 23,68 \\
\hline
\end{tabular}

Os valores de desvio padrão apresentados na tabela 6 , demostra o comportamento variável do volume explotado, o qual pode ser observado na figura 6.

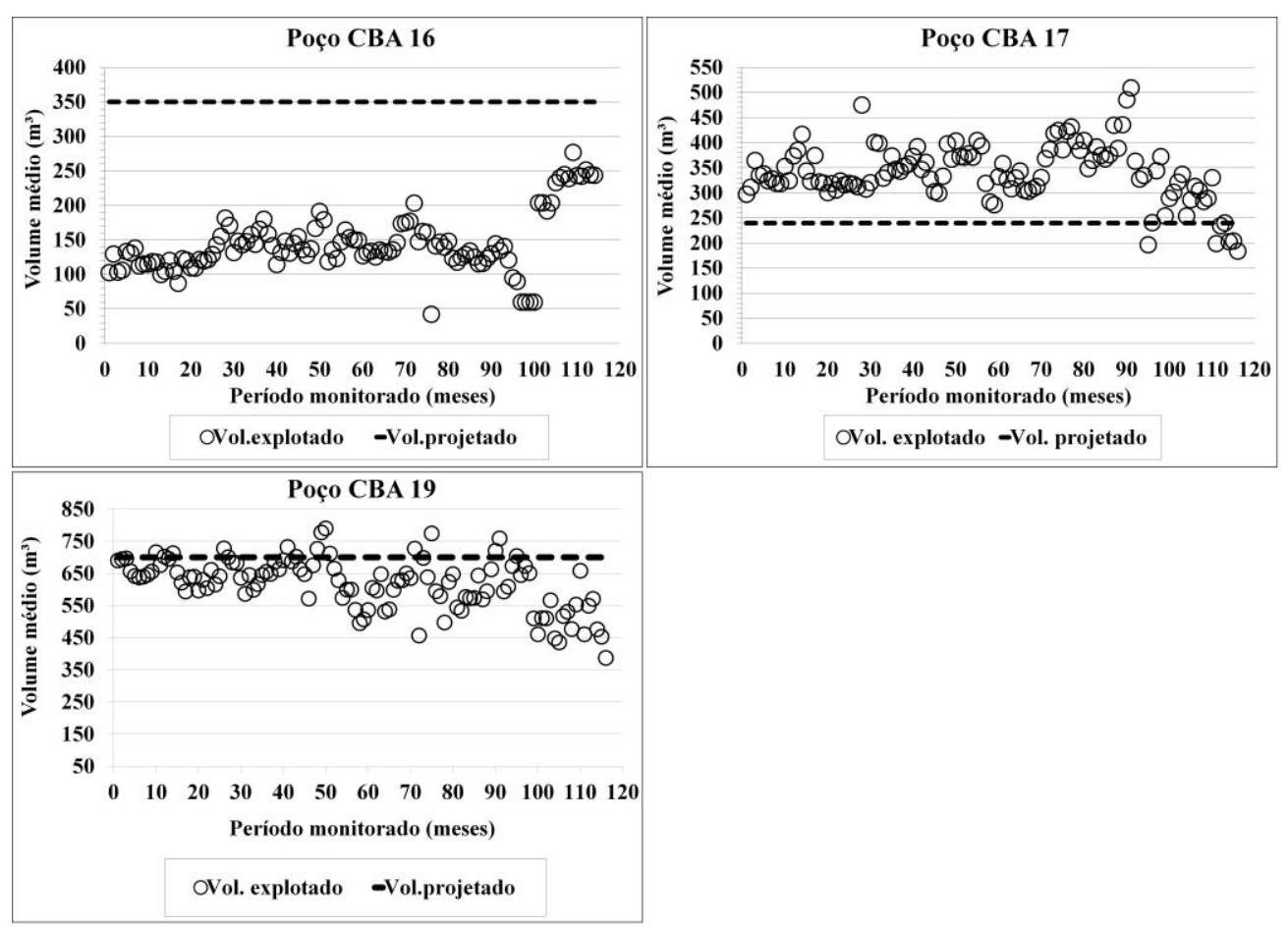

Figura 6. Valores médios mensais de volume de água nos poços utilizados para o abastecimento do reservatório $\mathrm{R} 3$. 
Mesmo com o comportamento habitual dos poços CBA 17 e 19, de explotarem volumes médios mensais acima do projetado, nos últimos anos (final de 2014 até maio de 2016), nesses dois poços foi observado uma redução dos valores de volume explotados. Nesse período, no poço CBA 19 o volume médio mensal explotado não ultrapassou o projetado, sendo que no poço CBA 17, após cerca de 8 anos, apresentaram uma redução significativa dos valores de volumes médio mensal de água explotado, chegando a ficar abaixo do projetado. Essa redução observada nesses dois poços, não correspondeu efetivamente a uma redução da demanda neste reservatório, pois no mesmo período ocorreu um aumento significativo nos valores de volume médio mensal explotados no poço CBA 16, conforme pode ser observado na figura 6.

\section{Diagnóstico do atendimento da demanda realizado através dos reservatórios $R 1, R 2, R 3$ e R4}

Nos três grupos de poços utilizados para abastecer os reservatórios foi identificado um problema de gestão, pois a distribuição da demanda entre os poços está sendo distribuída de forma heterogênea, sendo a mesma atendida de forma mais intensa por alguns poços do que em outros.

Nos últimos anos (final de 2014 até maio de 2016), o grupo de poços responsáveis pelo abastecimento dos reservatórios R3, foi o único a demostrar uma melhora em relação à falha na gestão descrita anteriormente. Neste grupo de poços, foi observado neste período um maior equilíbrio da distribuição da demanda entre os poços, sendo o volume explotado reduzido nos poços que comumente estavam extraindo valores superiores ao projetado e elevado no poço que habitualmente explotava valores significativamente inferiores a sua capacidade de produção.

Mesmo que atualmente, no grupo de poços responsável pelo abastecimento dos reservatórios R2 e R4 não haja nenhum poço explotando valores de volume médio mensal acima do projetado, a distribuição segue heterogenia, sendo que os poços CBA 10 e 12 apresentaram um aumento significativo do volume médio mensal explotado, enquanto os poços CBA 9 e 11 não apresentaram variação em seu comportamento, levando em consideração que o comportamento de elevação em dois meses no poço CBA 11 esta relacionado a ausência de bombeamento no poço CBA 10.

No grupo de poços responsáveis pelos reservatórios R1 a situação observada é mais crítica, em relação aos demais grupos, porque além da distribuição desigual da demanda entre os poços, a maioria deles, estão explotando volumes médios mensais acima do projetado e os que não se encontram nesta situação, estão operando com valores de volume médio mensal muito próximo do limite de projeto. Logo a demanda atualmente existente neste reservatório é superior à capacidade total de produção dos oito poços utilizados para o abastecimento do mesmo. 


\section{CONCLUSÃO}

Os dados de produção dos poços utilizados pela CORSAN para o abastecimento público de água no perímetro urbano de Carlos Barbosa, demostraram que a demanda atendida pelos 3 grupos de poços tubulares é dividida de forma heterogênea entre os poços de cada grupo.

Já está ocorrendo, na maioria dos poços do reservatório R1, uma extração de água média mensal, acima da projetada para o atendimento da demanda, indicando a necessidade de novas perfurações.

A demanda existente no reservatório R3, atualmente, está sendo distribuída de forma mais homogênea entre os poços, se encaminhando para uma operação de acordo com o projetado em todos os poços. No reservatório R2 e R4, mesmo com os poços trabalhando abaixo do projetado, ainda se faz necessário um replanejamento da operação dos mesmos, visando uma distribuição mais homogênea da demanda.

O reflexo do quadro atual da produção dos poços exposto neste trabalho no aquífero e difícil de ser estimado a partir do monitoramento quantitativo realizado nos poços pela CORSAN, o qual possuí algumas limitações, por ser manual e por depender da visita de um técnico para a realização do mesmo, contudo, esta situação possivelmente será sanada com o novo sistema de monitoramento implantado, o SIGAS.

\section{REVISÃO BIBLIOGRÁFICA}

IBGE - INSTITUTO BRASILEIRO DE GEOGRAFIA E ESTATÍSTICA. Pesquisa Nacional de Saneamento Básico - 2008. Rio de Janeiro, 2010.

LEAL, A.S. As águas subterrâneas no Brasil: Ocorrências, Disponibilidades e Uso. In: FREITAS, M.A.V. (Org.). O Estado das Águas no Brasil. Brasília: Agência Nacional de Energia Elétrica; Superintendência de Estudos e Informações Hidrológicas; Ministério do Meio Ambiente, Secretaria dos Recursos Hídricos, Ministério de Minas e Energia, 1999. 334p.

MOURÃO, M.A.A. Projeto "Implantação de Rede Integrada de Monitoramento das Águas Subterrâneas". $2009 . \quad$ Disponível em:< http://www.cprm.gov.br/publique/media/proposta_monitoramento_CPRM_2009.pdf > Acesso em: 12 de fevereiro, 2015.

PJS GEOLOGIA LTDA. Plano Municipal de Saneamento Básico de Carlos Barbosa Versão Preliminar 2013. 1. 2 Disponível em: http://www.carlosbarbosa.rs.gov.br/site/uploads/files/plano_\%C3\%81gua_esgoto_drenagem__vpre1.pdf> Acesso em: 17 de dezembro, 2014. 
REGINATO, P.A.R.; STRIEDER, A.J. Integração de Dados Geológicos na Prospecção de Aquíferos Fraturados na Formação Serra Geral. Revista da Associação Brasileira de Águas Subterrâneas. V.20, n.1, p. 1-14, 2006.

ROISENBERG, A.; VIERO, A.P. 2002. O Vulcanismo Mesozoico da Bacia do Paraná no Rio Grande do Sul. In: Holz, M.; De Ros, L.F. (Edit.). Geologia do Rio Grande do Sul. Porto Alegre: CIGO/UFRGS. Porto Alegre, 2000. 444p. il.- Edição Revista, 2002. 